\title{
Modifikasi Sistem Transmisi pada Mesin Pencacah Sampah/Limbah Plastik dengan Sistem Crusher dan Silinder Pemotong Tipe Reel
}

\section{Modification Of Transmission System In Machine Enumerator Garbage I Waste Plastic Crusher System With Cutting And Cylinder Type Reel}

\author{
Junaidi, Ichlas Nur, Zulfikar \& Nasirwan \\ Jurusan Teknik Mesin Politeknik Negeri Padang Kampus Limau Manis Padang \\ Telp. 0751-72590 Fax. 0751-72576
}

\begin{abstract}
An increasing number of plastic waste, but can be recycled into other products in the form of granules before further processing into a grain pellets and injection molding processes to produce products such as buckets, plates, bottles and others. To be processed into the required form of granules of plastic thrasher. Even so small plastic recycling industry is still constrained within a plastic enumeration process because the machine used his ability was not maximal.

The purpose of this study is a modification of the transmission system thrasher plastic crusher system and cylinder-type cutter reel and technical evaluation. This study was conducted over two years, the first year the design and manufacture of machinery, the second year is the technical evaluation of the engine, improved engine performance. From the results of the study year I found some weaknesses machines namely, 1) the machine is often hampered by the transmission belt on the motor shaft with shaft reducer as drive unit crusher often slip when a large load, 2) transmission gears hipoid of the motor shaft with shaft type unit reel get a great friction and cause the sound very noisy. To improve the performance of the engine of the transmission system needs to be fixed.

From the results of the design redesign the engine in the second year, namely, the installation of a connector axle of the motor shaft with shaft-type knife reel player. Axle used is commonly used in car axle Carry. Likewise, the transmission system between the motor shaft to the reducer as a successor to the rotation axis of the blade type crusher players use the chain sprocket to avoid slip on a rotating shaft. The results of performance testing crusher machine on lap 75 RPM and cylinder-type reel cutters 1450 RPM, engine capacity \pm $130 \mathrm{~kg} / \mathrm{h}$ on the cylinder type crusher and the reel-type cylinder engine capacity of $\pm 165 \mathrm{~kg} / \mathrm{h}$ at an aperture sieve $\varnothing 1,5 \mathrm{~cm}$, with uniformity of grain $85 \%$.
\end{abstract}

Keywords: Enumerators Crusher, waste plastic, the transmission system

\section{PENDAHULUAN}

Sampah plastik jumlahnya semakin lama semakin bertambah, dari 825 ton tahun 2006 meningkat 1038,5 ton pada tahun 2008 (Depperin 2009). Jumlah tersebut akan meningkat di tahun-tahun mendatang.

Secara umum agar suatu limbah plastik dapat diproses oleh suatu industri, antara lain limbah harus dalam bentuk tertentu seperti butiran, biji/pellet, serbuk, pecahan (Anonim, 2009). Untuk itu diperlukan beberapa mesin yang saling berhubungan, seperti mesin pencacah, mesin pembuat pellet dan mesin injection moulding, namun ketiga mesin tersebut hanya mampu dimiliki oleh industry menengah dan besar.Untuk industry kecil umumnya mereka menggunakan mesin pencacah untuk mendapatkan plastik dalam bentuk serpihan /butiran, dan kemudian serpihan ini yang dijual ke industri menengah dan besar. Disisi lain dari survey lapangan di Sumatera Barat dan khususnya di Kota Padang, lebih $\pm 80 \%$ industry pengolahan limbah plastik adalah industry kecil.

Teknologi pencacahan limbah plastik umumnya menggunakan mesin pencacah yang terdiri dari silinder pemotong tipe reel dan bedknife (pemotong diam). 
Bagaimanapun mesin pencacah tipe reel ini prosesnya kurang efisien karena proses pemotongan lama dan tenaga yang besar, mesin sering tersendat, pisau pemotong sering tumpul.

Untuk meningkatkan efisiensi proses pencacahan tersebut usaha perlu dilakukan 1) memperkecil ukuran bahan dengan pencacahan pendahuluan, 2) melakukan perusakan struktur bahan dengan meremukkan, menekan, menarik dan merobek-robek bahan, dengan keadaan ini bahan menjadi lebih lunak. Untuk itu perlu proses pencacahan pendahuluan menggunakan mesin pencacah berbentuk crusher.

Dari hasil penelitian tahap I telah dirancang dan dibuat prototype mesin pencacah plastik system crusher dan silinder pemotong tipe reel dengan kapasitas secara teori $\pm 350 \mathrm{~kg} / \mathrm{jam}$. Ukuran kontruksi mesin yaitu $100 \mathrm{~cm}$ x $120 \mathrm{~cm} \mathrm{x}$ $30 \mathrm{~cm}$, daya motor penggerak $10 \mathrm{HP}$ dengan putaran 1450 RPM dengan 3 phase. Beberapa komponen utama dari mesin yaitu, unit pencacah crusher terdiri dari dua buah silinder pencacah yang berputar berlawanan, poros pencacah berukuran $\varnothing 4$ $\mathrm{cm} \times 58 \mathrm{~cm}$, pisau pencacah $\varnothing 17 \mathrm{~cm} \times 2$ $\mathrm{cm}$ dengan jumlah gigi/mata pisau 7 buah dan jumlah pisau sepanjang poros 7 buah, bus penahan $\varnothing 10 \mathrm{~cm}$ x $2 \mathrm{~cm}$. Unit pencacah silinder pemotong tipe reel terdiri dari poros pencacah ukuran $\varnothing 4 \mathrm{~cm} \times 90$ $\mathrm{cm}$, ditengah poros terpasang silinder dengan $\emptyset 17 \mathrm{~cm}$ x $40 \mathrm{~cm}$ sebagai dudukan dari pisau pencacah. Pisau pencacah berjumlah 4 buah dengan ukuran $40 \mathrm{~cm} \times 2$ $\mathrm{cm} \times 4 \mathrm{~cm}$ dengan bahan ASSAB. Selanjutnya bedknife sebagai pisau penahan gaya geser dari pisau pencacah, rangka atas, rangka bawah, saringan, corong masuk, corong keluar, dan unit penggerak terdiri dari motor listrik, reducer, sabuk, pully dan 2 buah transmisi roda gigi. Dari hasil pengujian kinerja mesin pada putaran crusher 145 RPM dan silinder pemotong tipe reel $1400 \mathrm{RPM}$ didapatkan kapasitas mesin $\pm 200 \mathrm{~kg} / \mathrm{jam}$ pada $\varnothing$ lobang saringan $1,5 \mathrm{~cm}$, dengan keseragaman butiran $\pm 60 \%$. Selanjutnya akan dilakukan penelitian tahun ke II dengan subjek penelitian adalah evaluasi teknis mesin pada berberapa sudut pisau tipe reel dengan berapa putaran dan beberapa $\varnothing$ lobang saringan, kemudian melakukan perbaikan kinerja mesin dan analisis ekonomi terhadap produk hasil cacahan plastik.

Dari pengujian mesin didapatkan beberapa kelemahan mesin yaitu, 1) mesin sering tersendat karena transmisi sabuk pada poros motor dengan poros reducer sebagai penggerak unit crusher sering slip pada saat beban besar, 2) transmisi roda gigi hipoid dari poros motor dengan poros unit tipe reel mendapatkan gesekan yang besar dan menimbulkan suara yang sangat bising. Untuk meningkatkan kinerja mesin maka perlu diperbaiki sistem tranmisi tersebut.

Tujuan penelitian ini adalah modifikasi sistem transmisi mesin pencacah plastik sistem crusher dan silinder pemotong tipe reel. Transmisi penghubung antara poros motor dengan poros reducer harus mampu menggerakkan unit crusher secara kontinyu pada saat beban besar, begitu juga sistem transmisi penghubung poros motor dengan poros unit tipe reel.

Mesin harus mampu mencacah plastik secara efisien, proses kerja menjadi lebih cepat, kapasitas lebih besar dan dengan daya kecil dibandingkan mesin sebelumnya.

\section{Sampah/Limbah Plastik}

Plastik adalah suatu produk kimia yang telah dikenal dan termasuk bagian polimer termoplastik. Sebagai material yang tidak dapat terdegradasi secara alami, plastik menyebabkan masalah lingkungan yang semakin besar (Sumule, 2006).

Limbah plastik dapat di daur ulang, adapun proses daur ulang tersebut melalui beberapa tahapan yaitu, proses penghancuran menjadi bagian-bagian yang lebih kecil berbentuk serpihan yang seragam berukuran $1-1,5 \mathrm{~cm}$. Proses ini membutuhkan mesin pencacah dengan teknologi tepat guna. Bentuk dari serpihan 
plastik yang telah dihancurkan/dicacah seperti gambar 1, 2, 3, dan 4 dibawah ini. (http://www.geocities.com/tegal logam 2000).

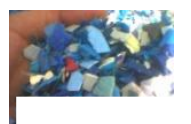

a

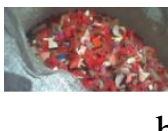

b

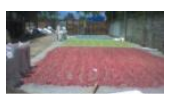

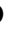

c

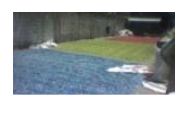

Gambar 1. Butiran plastik yang telah dicacah

Keterangan:

1a. Bentuk butiran kasar $(1,5 \mathrm{~cm}$

1b. Bentuk butiran halus $(1 \mathrm{~cm})$

1c. Butiran yang telah diwarnai (merah)

1d. Butiran yang telah diwarnai (biru)

Tahap selanjutnya adalah mewarnai, dan pengeringan dilapangan. Untuk industri plastik skala menengah keatas pada umumnya mereka sudah punya mesin pellet dan mesin Injection Moulding. Dengan mesin pellet ini plastik serpihan dapat dibuat dalam bentuk biji/pellet, begitu juga pellet plastik dapat diproses dengan mesin injection moulding menjadi bermacammacam hasil plastik, seperti ember, piring plastik, botol minuman, tabungan plastik, dan lain-lain.

Sukatna (2007), mengatakan semua pabrik plastik daur ulang (recycling) membutuhkan plastik-plastik bekas (sampah plastik) baik dari kelompok film grade (sampah plastik lembaran kemasan makanan seperti : kantong gula, tepung, kantong belanja (kresek), kantong sampah, pembungkus tekstil, tas, garmen, pembungkus rokok, pembungkus baju/kaos, karung plastik, dan lain-lain), maupun dari non-film grade (botol air mineral, juice, saos, minyak goreng, kosmetik, shampoo, oli, tutup botol, krat botol, ember, mainan, tong sampah, container, pipa PVC, kabel listrik, selang air, plastik gelombang, dan lain-lain). Plastik-plastik tersebut sebagai bahan utama/campuran untuk diproses daur ulang menjadi biji/pellet plastik, sehingga dikenal dengan nama biji/pellet plastik daur ulang. Hal ini hanya untuk membedakan dengan biji plastik original (asli). Karena biji plastik asli sebagian besar masih impor, sehingga harganya cukup mahal (tergantung dolar dan harga minyak dunia). Maka biji/pellet plastik daur ulang dapat menjadi suatu alternatif, dengan harga yang sangat kompetitif. Dan tentu saja bisnis ini sangat prospektif.

\section{Tipe Mekanisme Alat Pencacah}

\section{Alat Pencacah Kompos}

Alat pencacah kompos (Gambar 2) merupakan salah satu alat yang dapat membantu dalam proses pembuatan kompos secara anaerob dengan bahan baku khususnya sampah organik dengan memperkecil ukuran (Sudrajat 2006).

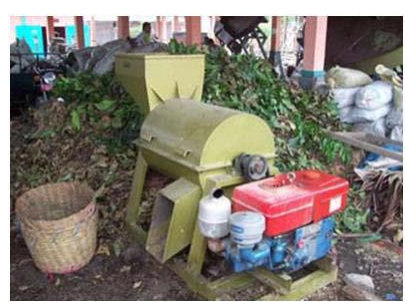

Gambar 2. Alat pencacah kompos (Sudrajat 2006

Sistem kerja alat ini pada dasarnya sama dengan gilingan martil (hammer mill). Menurut Kong Hwan Kim 1989 martil (hammer) pada mesin (hammer mill) berfungsi sebagai batang pemukul atau dapat juga diganti dengan batang pisau pemotong. Proses yang terjadi adalah bahan atau material seperti serat, dedaunan, sayuran dimasukkan ke dalam hammer mill yang berputar kemudian produk yang dihasilkan menjadi ukuran yang lebih kecil (size reduction).

\section{Tub Grinders}

Tub grinder (Gambar 3) adalah alat khusus yang digunakan untuk memotong/membelah (chopping) kayu termasuk di dalamnya batang dan dedaunan dalam jumlah yang besar. Sistem kerja dari tub grinder ini adalah sistem kerja pisau pemotong (hammer mill) yang bergerak secara horizontal 


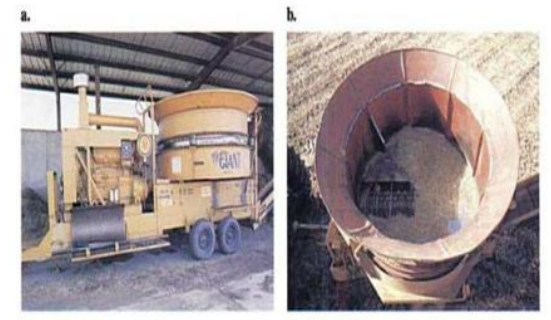

Gambar 3. Tub grinders (Robert 1995).

\section{Crushing}

Crushing adalah alat pencacah yang banyak digunakan pada bahan-bahan pertanian dan limbah-limbah padat yang bertujuan untuk memperkecil ukuran bahan, merusak struktur bahan untuk memudahkan pencacahan dan menghaluskan bahan dalam bentuk serbuk.

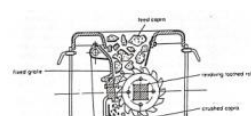

a

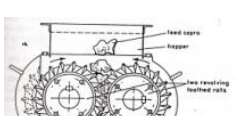

b

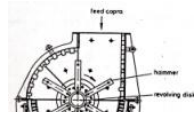

Gambar 4. Sistem Crushing pada Bahan Pertanian dan Limbah Padat (Thieme, 1969)

\section{Keterangan:}

4a. Pisau berputar secara horizontal pada satu poros (single roll)

4b. Pisau berputar secara horizontal dan tersusun pada dua poros (double roll) yang berputar berlawanan

4c. Alat pencacah terdiri dari palu-palu yang tersusun secara melingkar, sambil berputar palu-palu akan menghancurkan bahan secara berulang kali

Pada Gambar 4 adalah proses crushing pada kopra menjadi partikel kecil untuk memudahkan ekstraksi minyak dan akibatnya hasil akan meningkat. Crushing dilakukan dalam dua tahap. Pada tahap pertama adalah pencacahan kopra menjadi ukuran yang kecil berbentuk serpihan

\section{Tipe Pisau Pemotong}

Pisau pemotong rumput dibedakan menjadi dua berdasarkan tipe pisau pemotong yaitu pisau pemotong rumput tipe reel dan tipe slasher.

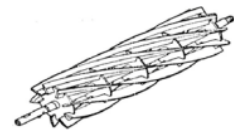

a. Tipe Reel

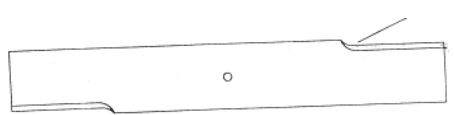

b. Tipe Slasher
Gambar 5. Jenis-jenis pisau pemotong rumput (Mardison 2000).

Pisau pemotong rumput tipe slasher terdiri dari satu bilah pisau yang digerakkan secara rotasi dengan kecepatan tinggi, sehingga menghasilkan daya pukul yang kuat untuk memotong rumput (Mardison 2000). Pisau pemotong rumput tipe reel memberikan hasil potongan rata pada bagian tajuk rumput yang dipotong sehingga tidak mengganggu pertumbuhan rumput. Pisau pemotong rumput tipe slasher memberikan hasil potongan yang tidak baik pada bagian tajuk rumput, di mana tajuk rumput bekas potongan jadi pecah dan hasil potongan tidak rata (Beard 1993).

\section{Metode Pemotongan Bahan Pertanian}

Pemotongan (Cutting) bahan - bahan hasil pertanian sering dilakukan pada saat panen (harvesting), dalam pemisahan (separation) dan juga dalam proses pengecilan (comminution) ukuran bahan .

Pada saat pemotongan, mata pisau menembus ke dalam bahan, melewati kekuatan bahan sehingga bahan menjadi terpisah. Pada saat pemotongan berlangsung, terjadi perbedaan deformasi pada bahan, yang tergantung pada bentuk mata pisau dan proses kinematik pemotongan (Sitkey 1986). Gambar 6a memperlihatkan proses pemotongan yang menggunakan dua mata pisau yang saling berhadapan dan terlibat pemotongan (countermoving blade). Contoh untuk kasus ini adalah gunting. Gambar 6b memperlihatkan tipe alat potong di mana bahan diletakkan pada landasan yang diam dan pisau pemotong bergerak. Contoh praktis pada proses ini adalah pada perajangan keripik singkong dengan alat 
chipper. Gambar 6c mengilustrasikan pemotongan lapisan yang tipis, di mana distribusi tegangan di sekitar mata pisau mengalami distorsi yang sangat besar akibat permukaan bebas pada sekitar bidang pemotongan. Gambar $6 \mathrm{~d}$ menunjukkan metode pemotongan bebas (free cutting) yang saat ini banyak dilakukan. Pada kasus ini kecepatan mata pisau harus tinggi (20 $40 \mathrm{~m} / \mathrm{s}$ ) (Sitkey 1986).

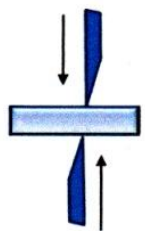

(a)

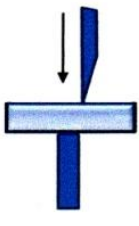

(b)

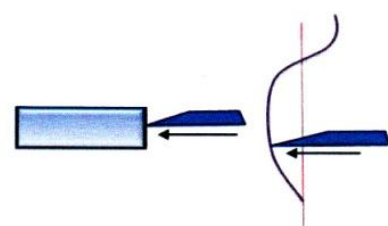

Gambar 6. Beberapa Metode

Pemotongan (Sitkey 1986).

\section{Pemotongan Limbah Padat}

Proses mendaur ulang limbah padat pada umumnya dengan proses pengecilan ukuran bahan melalui proses pemotongan atau pencacahan. Secara umum gaya dan energi pemotongan bahan padat akan dipengaruhi oleh disain pisau, cara operasi, dan sifat bahan padat yang akan dipotong.

Beberapa kajian penggunaan mata pisau untuk pemotongan limbah padat, seperti limbah batang jagung (Prasad dan Gupta, 1975), rumput dan jerami (O’Dogherty dan Gale, 1991 ; McRandall dan McNulty, 1978). Gergaji bulat seringkali juga digunakan untuk memotong limbah padat lainnya. Rao dan Thrupal (1990), Kanaka dan Thiupal (1991) telah mengembangkan mesin pemotong tebu dengan gergaji bulat dengan kecepatan sekitar 2000 rpm. Hutton dan Lee (1992) mempelajari penggunaan gergaji bulat untuk pemotongan kayu. Dilaporkan bahwa gergaji dengan bevel angel $15^{\circ}$ memberikan hasil yang lebih baik daripada gergaji konvensional. Williston (1978) menyimpulkan bahwa tenaga pemotongan kayu dipengaruhi oleh faktor seperti jumlah gigi pada gergaji bulat, putaran, dan kekerasan bahan. Kollman et al. (1975) menjelaskan bahwa kapasitas mesin pencacah kayu dipengaruhi oleh ketebalan irisan, spesies kayu, ukuran, kadar air bahan yang dipotong, ketajaman pisau.

Hadi et al. (2001) telah mengembangkan komponen pencacah tandan kosong sawit yang mempunyai dua buah pisau yang diputar dengan motor listrik. Hasil evaluasi teknis menunjukkan bahwa kecepatan putar pisau yang sesuai adalah sekitar $750 \mathrm{rpm}$ dimana kapasitas pencacahannya $\quad 1.816 \quad \mathrm{~kg} / \mathrm{jam}$. Bagaimanapun juga komponen ini hanya bisa digunakan untuk mencacah tandan kecil. Tandan besar akan terjepit pada celah antara pisau dan penutupnya.

Untuk mengatasi hal itu, Hadi et al. (2001) telah mengembangkan model mesin pencacah dengan dua tahap kerja, yaitu tahap pertama pencacahan pendahuluan dengan sistem crusher dan tahap kedua dengan dua pisau pencacah berputar. Crusher dimaksudkan untuk merusak struktur tandan dan mengurangi ketebalannya sehingga akan lebih mudah dicacah. Tandan utuh yang diumpankan kedalam mesin akan terjepit dan bergerak diantara dua silinder yang dilengkapi dengan gigi metal disekelilingnya. Sedangkan mesin pencacah mempunyai komponen utama berupa dua buah pisau yang dipasang pada sebuah silinder dan diputar dengan menggunakan energi listrik. Tandan akan dicacah secara kontinyu oleh pisau yang berputar dan hasilnya akan terlempar keluar. Hasil evaluasi teknis crusher menunjukkan bahwa perusakan struktur tandan akan memudahkan proses pencacahan. Ketebalan tandan akan berkurang sekitar 33\% dari rata-rata 26,6 $\mathrm{cm}$ menjadi $17,7 \mathrm{~cm}$; hal ini akan memudahkan pencacahannya. Sedangkan kapasitas pencacahannya adalah 4.124 $\mathrm{kg} / \mathrm{jam}$ dari sebelumnya $2.847 \mathrm{~kg} / \mathrm{jam}$.

Selain itu kajian tentang efisiensi kerja mesin dalam proses pengolahan limbah padat disamping proses pemotongan juga dilakukan pada proses lainnya, seperti proses penguraian serat sabut kelapa. Proses penguraian dan pemisahan serat prinsipnya adalah merobek, menarik, memutus dan menghempaskan bahan baku 
sabut, sehingga ikatan antara serat dan gabus-gabus dapat terpisah. Untuk mempermudah proses kerja dilakukanlah proses pendahuluan dengan proses pencincangan sabut kemudian dipress atau bahan sabut dihempaskan dengan putaran tinggi agar strukturnya rusak dan bahan menjadi lunak. Hal ini juga dilakukan oleh Wahyu. K (2011), dalam proses pencincangan sarasah tebu untuk dijadikan kompos. Untuk efisensi kerja mesin pencincang menggunakan tiga proses kerja yaitu, pengambilan sarasah dengan menggunakan komponen sepasang silinder yang permukaannya dipasang besi-besi bulat lurus yang berputar berlawanan, system konveyor dan system auger.

\section{Hasil Penelitian Tahun ke I}

Bentuk mesin yang telah didesain ulang seperti pada Gambar 7, dan hasil prototype mesin yang telah selesai dibuat dan diassembling seperti pada Gambar 8.

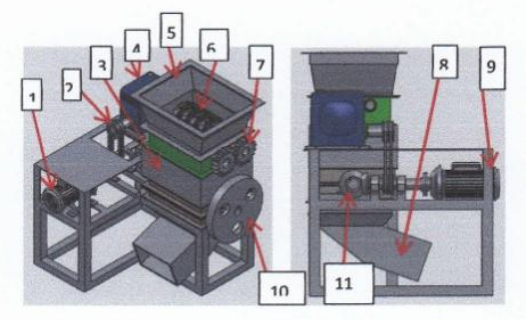

Gambar 7. Rancangan Prototipe Mesin Th I


Gambar 8. Prototype Mesin Pencacah Plastik

\section{METODOLOGI}

Pada tahun kedua penelitian dilaksanakan selama 8 bulan dan difokuskan pada beberapa kegiatan yaitu:

1. Modifikasi rancangan mesin dengan memodifikasi sistem transmisi pada unit pencacah sistem crusher dan sistem tipe reel. Pada tahun I dari hasil pengujian kinerja mesin yang telah dilakukan di dapatkan beberapa kelemahan mesin yang membuat kinerja mesin tidak maksimal yaitu: 1) mesin sering tersendat karena transmisi sabuk pada poros motor dengan poros reducer sebagai penggerak unit crusher sering slip pada saat beban besar, 2) transmisi roda gigi hipoid dari poros motor dengan poros unit tipe reel mendapatkan gesekan yang besar dan menimbulkan suara yang sangat bising. Bentuk sistem transmisi penelitian tahun I seperti Gambar 9. Modifikasi dilakukan dengan memasang transmisi gardan pada unit pisau tipe reel, karena gardan mampu sebagai penerus putaran dengan beban besar tanpa adanya bunyi yang bising, begitu juga pemasangan transmisi rantai dengan sproket pada unit pisau tipe crusher dilakukan karena transmisi rantai tidak ada slip dengan penggunaan pada beban besar. Bentuk transmisi rantai dengan sproket seperti pada Gambar 10.

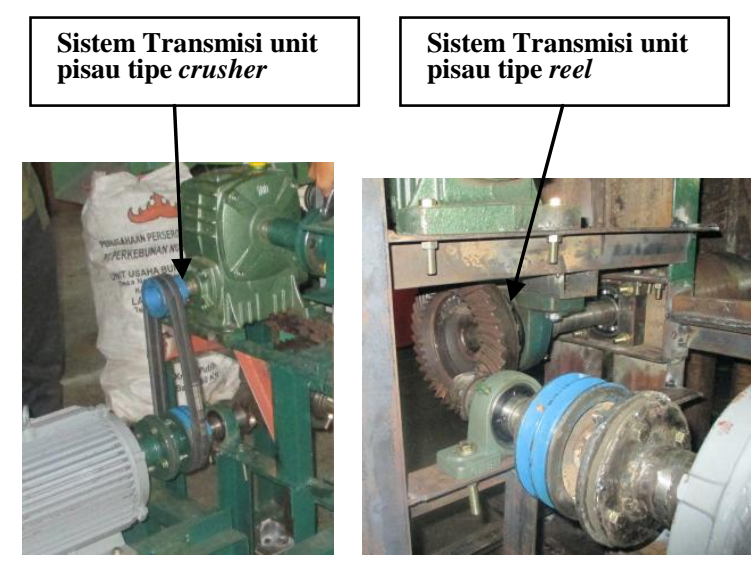

Gambar 9. Sistem Transmisi Mesin pencacah plastik penelitian tahun I 


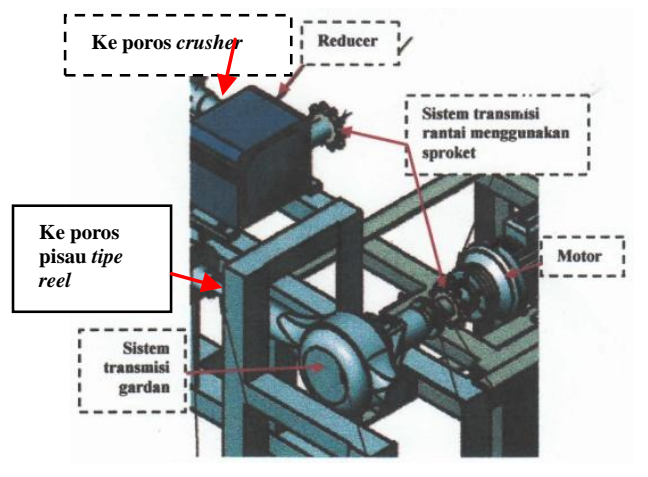

Gambar 10. Sistem Transmisi Hasil Modifikasi

2. Pembuatan sistem transmisi hasil modifikasi dan assembling.

3. Pengujian kinerja mesin.

\section{HASIL DAN PEMBAHASAN}

\section{Prototype Mesin}

Modifikasi rancangan mesin difokuskan kepada sistem transmisi penggerak unit crusher dan unit tipe reel, bentuk mesin seperti diperlihatkan pada Gambar 11.

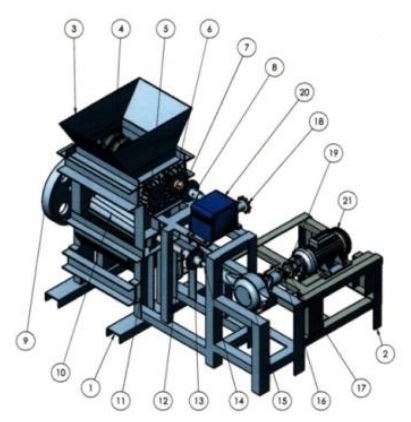

Gambar 11. Model 3-D Hasil Rancangan

\section{Keterangan :}

\section{Rangka}

2. Dudukan motor

3. Pisau tipe reel

4. Reducer

5. Roda gigi wheel

6 . Roda gigi pinion

7. Poros pisau pencacah

8.Kopling pisau pencacah

9. Roda gila

10. Pisau bawah

11. Bearing

Sistem transmisi yang dimodifikasi pada mesin yaitu pemasangan gardan sebagai penghubung dari poros motor dengan poros pemutar pisau tipe reel. Gardan yang digunakan adalah yang biasa digunakan pada gardan mobil Carry. Begitu juga sistem transmisi antara poros motor dengan reducer sebagai penerus putaran ke poros pemutar pisau tipe crusher menggunakan rantai sproket untuk menghindari terjadinya slip pada poros berputar. Ukuran dan dimensi gardan seperti pada Gambar 12. Diameter rumah gardan tegak lurus dengan poros penggerak adalah $18 \mathrm{~cm}$, diameter rumah poros penggerak unit pisau tipe reel adalah 6,4 $\mathrm{cm}$, poros penggerak unit pisau tipe reel dengan diameter $2,4 \mathrm{~cm}$ dan panjangnya 40,6 cm (Gambar 13). Pada ujung poros gardan penggerak dan yang digerakkan dipasang kopling tetap sebagai penghubung dengan poros motor dan dengan poros penggerak unit pisau tipe reel (Gambar 14)
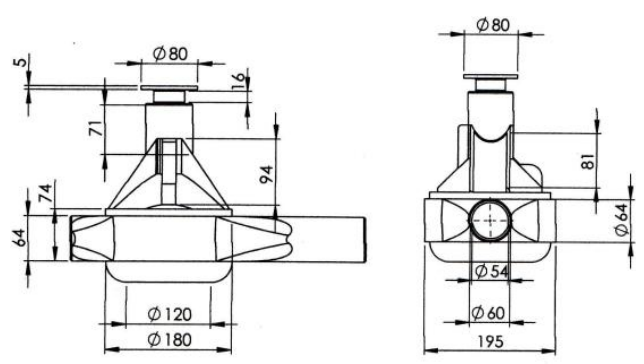

Gambar 12. Ukuran dan dimensi Gardan
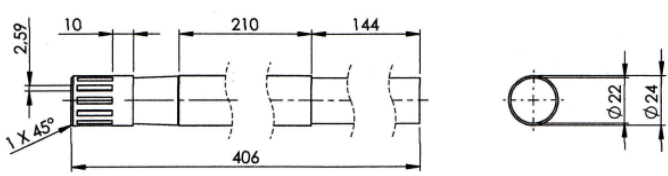

Gambar 13. Poros penggerak unit pisau tipe reel 


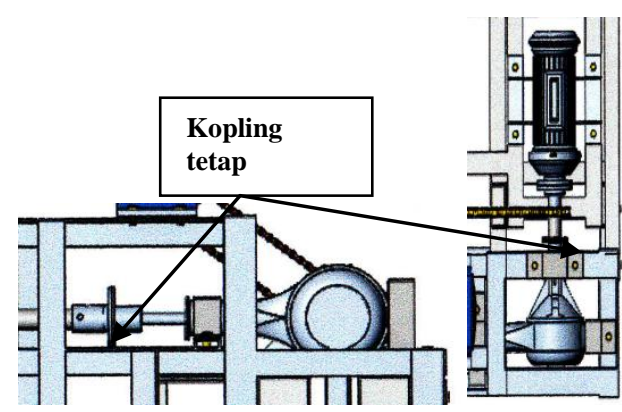

Gambar 14. Kopling tetap

Bentuk sistem transmisi gardan dan sistem transmisi rantai sproket secara keseluruhan seperti Gambar 15.

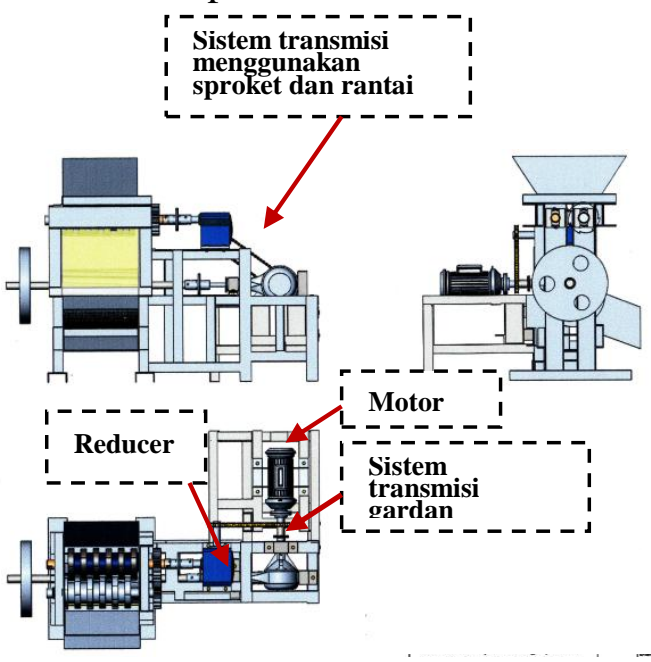

Gambar 15. Mesin pencacah plastik dengan sistem transmisi yang dimodifikasi

\section{Pembuatan Komponen Sistem transmisi hasil modifikasi.}

Setelah didisain ulang mesin pencacah plastik ini kemudian dilakukan pembuatan komponen-komponen yang dimodifikasi. Komponen unit gardan pada sistem transmisi antara poros motor dengan poros penggerak pisau tipe reel menggunakan gardan yang bisa digunakan pada mobil carry. Pada gardan mobil terdapat 3 poros yang berputar bersamaan. Poros ditengah adalah sebagai penggerak dari engine dan dengan perantaraan roda gigi hipoid maka poros yang kedua dan ketiga berputar menggerakkan roda. Penggunaan gardan pada mesin pencacah plastik ini dimodifikasi agar dapat menggerakkan unit pisau tipe reel dengan putaran yang sama.
Modifikasi dilakukan dengan dengan memotong kedua lengan sebagai dudukan poros, dan mematikan satu lengan gardan, dengan demikian gardan hanya punya satu poros penggerak dan satu poros yang digerakkan. Beberapa komponen dari gardan yang dibuat agar bisa sebagai penggerak yaitu, membuat poros gardan, memasang dudukan bantalan, membuat plat penahan bantalan, dan membuat kopling tetap penghubung dengan poros motor, sekaligus sebagai dudukan sproket. Sedangkan modifikasi transmisi pada unit pisau crusher yaitu, membuat poros dudukan sproket, membuat bus pemegang poros reducer dengan poros dudukan sproket. Bentuk gardan seperti pada Gambar 16 dan assembling gardan seperti Gambar 17.

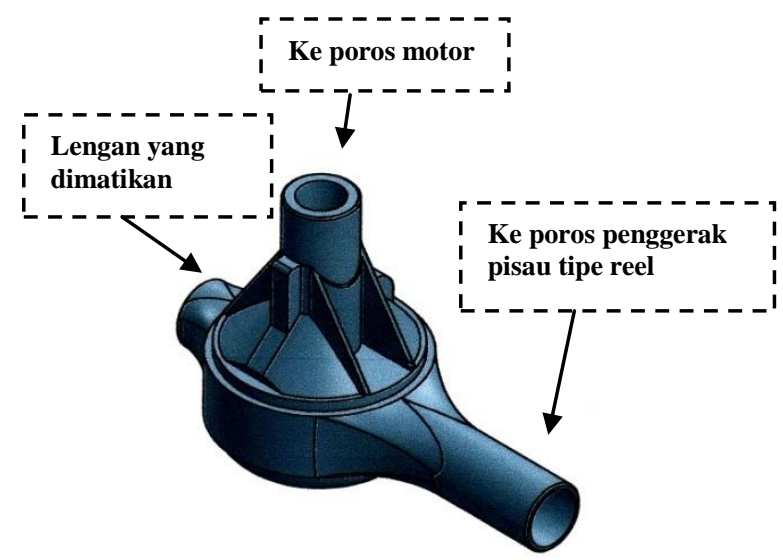

Gambar 16. Rumah gardan

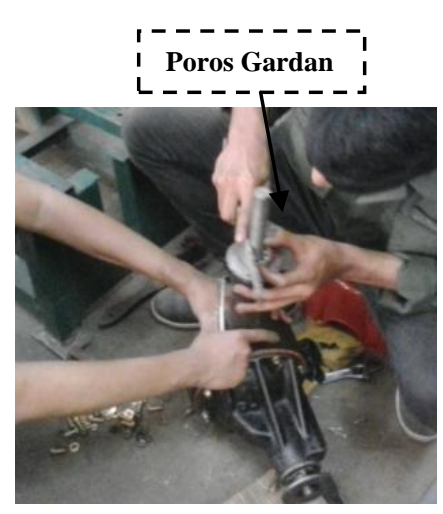

Gambar 17. Assembling Gardan hasil Modifikasi 


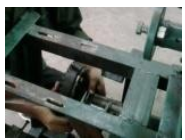

a

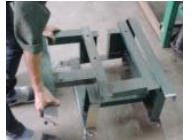

b

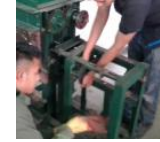

c



d
Gambar 18. Proses Modifikasi Dudukan Gardan

Modifikasi rumah gardan disesuaikan dengan dudukan pada rangka mesin (Gambar 18a). Kemudian poros gardan dimodifikasi disesuaikan letak motor dengan poros penggerak pisau tipe reel (Gambar 18b). Proses selanjutnya adalah memodifikasi dudukan motor penggerak dan dudukan gardan (Gambar 18c), dan setelah gardan terpasang pada rangka dan kemudian mencocokannya dengan poros motor. Kemudian memasang sproket pada poros reducer dengan poros motor dan memasang rantai kemudian menguatkannya. Setelah semua terpasang kemudian menguatkan semua komponen yang terpasang. Hasil assembling mesin dengan memasang semua komponen sistem transmisi hasil modifikasi seperti pada Gambar 19.

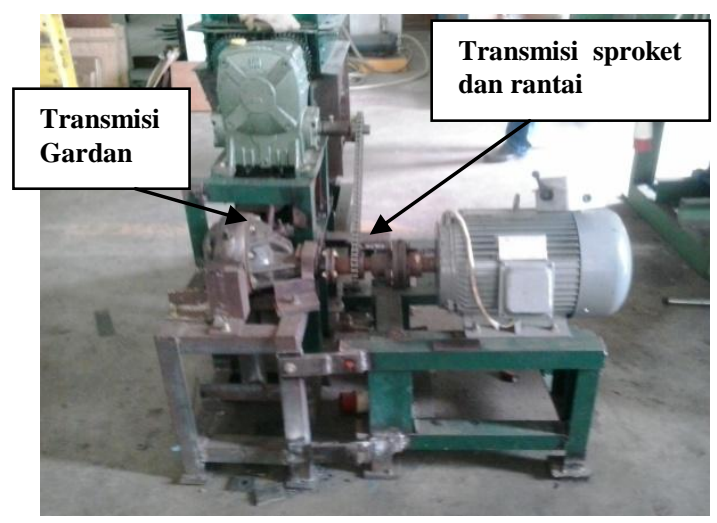

Gambar 19. Mesin pencacah Plastik hasil modifikasi

\section{Pengujian Kinerja Mesin}

Setelah seluruh komponen transmisi selesai dibuat selanjutnya dilakukan pemasangan dudukan transmisi pada rangka. Poros motor menggerakkan sekaligus dua poros, yaitu poros pada unit pisau tipe crusher dan unit pisau tipe reel.
Setelah itu proses pemasangan komponen transmisi dan dudukan motor penggerak.

Selanjutnya dilakukan pengujian kinerja mesin pencacah hasil modifikasi. Selama uji coba seperti proses pencacahan pendahuluan pada pencacah crusher dan pencacah tipe reel proses pemotongan lancar, unit pisau crusher dan unit pisau tipe reel berputar secara kontinyu, dan pada saat diberi beban dengan memasukkan plastik kedalam corong masuk proses pemotongan berjalan lancar, mesin tidak tersendat dan tidak menimbulkan gesekan yang besar sehingga bunyi gardan sangat kecil. Hasil uji coba mesin pencacah disajikan dalam Tabel 1.

Tabel1. Hasil analisis pengujian mesin

\begin{tabular}{|l|l|l|l|}
\hline Analisis & $\begin{array}{l}\text { Ukuran } \\
\text { Plastik }(\mathrm{cm})\end{array}$ & $\begin{array}{l}\text { Kapasitas } \\
\mathrm{kg} / \mathrm{jam}\end{array}$ & $\begin{array}{l}\text { Keseragaman } \\
\text { butiran }(\%)\end{array}$ \\
\hline $\begin{array}{l}\text { Sebelum } \\
\text { pencacahan }\end{array}$ & $8-20$ & 0 & 0 \\
\hline $\begin{array}{l}\text { Pencacah } \\
\text { crusher }\end{array}$ & $2-4$ & 130 & 50 \\
\hline $\begin{array}{l}\text { Pencacah } \\
\text { tipe reel }\end{array}$ & $0,5-1,5$ & 165 & 85 \\
\hline
\end{tabular}

Hasil pada table 1 memperlihatkan ukuran plastik sebelum dicacah dengan ukuran yang tidak merata antara $8-20 \mathrm{~cm}$. Setelah masuk kedalam pencacah crusher bahan diremukkan, ditarik dan dipotong menjadi ukuran 2-4 cm, dan keseragaman bahan $\pm 50 \%$. Proses pencacahan dengan pemotong crusher merupakan pencacahan pendahuluan, yang mana bahan diperkecil sebelum masuk kedalam pencacah tipe reel. Setelah bahan masuk kepencacah tipe reel ukuran bahan sudah lebih kecil dan struktur bahan sudah lunak, sehingga pada waktu jatuh masuk ke pencacah tipe reel bahan mudah dicacah. Pada saat bahan dicacah oleh pisau, hasil cacahan dibawa oleh mata pisau kebawah melalui saringan. Sambil membawa bahan, pisau pencacah juga menghempaskan dan memaksa bahan masuk kedalam saringan dengan ukuran yang sama. Pada saat pengujian ukuran saringan $1,5 \mathrm{~cm}$, dengan adanya saringan maka tingkat keseragaman bahan lebih besar. 


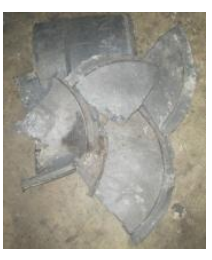

a

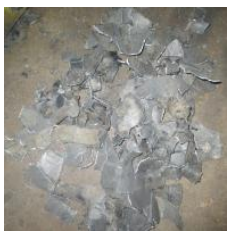

b

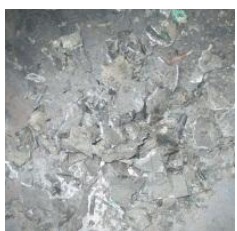

C
Gambar 20. a) ukuran sebelum dicacah, b) hasil cacahan pisau Crusher, c) hasil cacahan pisau tipe reel

\section{SIMPULAN}

Pada penelitian tahun ke II telah dimodifikasi mesin pencacah plastik dengan memasang transmisi gardan antara poros motor dengan poros penggerak pisau tipe reel, kemudian memasang sistem transmisi rantai sproket antara poros motor dengan poros reducer sebagi penggerak poros crusher untuk menghindari slip pada saat motor memutar reducer. Dari hasil kinerja mesin pergerakan dari unit penggerak pisau tipe reel dan unit pisau sistem crusher berjalan dengan maksimal, baik pada saat tidak diberi bahan maupun pada saat bahan plastik dimasukkan dan dicacah oleh kedua unit pisau mesin. Pada unit crusher tidak ada slip, poros berputar terus pada saat dikasih beban dan pada unit tipe reel putaran poros pemegang pisau tipe reel juga bergerak secara terus menerus. Kapasitas mesin $\pm 165 \mathrm{~kg} / \mathrm{jam}$ setelah keluar pada saringan.

\section{UCAPAN TERIMA KASIH}

Terima kasih kepada Politeknik Negeri Padang yang telah mendanai kegiatan ini melalui penelitian Unggulan Perguruan Tinggi dana DIPA Politeknik Negeri Padang Tahun ke II dengan no. kontrak 262 / PL9. 1.4 / LT/ 2015. Kemudian juga terima kasih kepada Bapak Tim Reviwer, teman-teman Staf Pengajar Jurusan Teknik Mesin Politeknik Negeri Padang dan Mahasiswa yang telah membantu dalam pembuatan dan perbaikan serta pengujian mesin ini.

\section{DAFTAR PUSTAKA}

Hadi, N. 2006. Ancaman Polimer Sintetik Bagi Kesehatan Manusia. Desertasi S3Biokimia. http://www.chem.

Hadi Suryanto, Djamri Amir, dan Teguh B (2002). Pengembangan Prototype Mesin Pencacah Tandan Sawit untuk menghasilkan Bahan Baku pupuk Organik. TPSDP. SPK No. 18/II/TPSDP-Unand/4-2002.

Hunt, D.R. 1986. Engineering Models For Agricultural Productions. The AVI Publshing Company Inc. Wesport, Connecticut.

Hutton, S.G. dan V. Lee. 1992. Effect of Tooth Front Bevel Angle on Cutting Accuracy and Chip Formation for Circular Rip Saw". Holz als Roh-und Werkstoff. 50:313-316.

Iklas.N, Junaidi. 2009. Rancang Bangun Mesin Pencacah Plastik Untuk Meningkatkan Produktivitas Usaha Kecil Plastik Bekas. Laporan Program VUCER Dikti 2009. No Kontrak: 160 A / K3.1-PG / 2009.

Iklas. N. 2014. Pengembangan Mesin Pencacah Sampah/Limbah Plastik dengan Metode Kombinasi Sistem Crusher dan Silinder Pemotong Tipe Reel. Laporan Penelitian AUPT dana BOPTN PNP tahun I. Kontrak: 443 / PL9. 1.4 / LT 2014.

Iklas. N. 2014. Pengembangan Mesin Pencacah Sampah/Limbah Plastik dengan Metode Kombinasi Sistem Crusher dan Silinder Pemotong Tipe Reel. Laporan Penelitian AUPT dana BOPTN PNP Tahun II. Kontrak: 443 / PL9. 1.4 / LT 2015

Kanaka P.R. dan K. Thiupal. 1991. "Seedcane Cutting Machine". Indian Sugar. 41(2):125-126.

Mardison. 2000. Rancang Bangun Pisau Pemotong Rumput Tipe Reel dengan 
Menggunakan Paket Program CAD (Skripsi). Bogor. Fakultas Teknologi Pertanian Bogor.Institut Pertanian Bogor.

McRandall, D.M. dan P.B. McNulty. 1980. "Impact Cutting Behaviour of Forage Crops”. J. Agric. Engng. Res. 313328.

Newman. G, 1990. Engineering Ekonomic Analysis, Third Edition, Binarupa Aksara Engineering Pres, Inc.

Pemerintah kota Padang, Bidang Pengelolaan Sampah. http://www.Padang.go.id.

Prasad, J. Dan C.P. Gupta. 1975. Mechanical Properties of Maize Stalk as Related to Harvesting. J. Agric. Engng. Res. 20:79-87.

Rao, KKP dan K. Thirupal. 1990. "Sugarcane Cutting Machine". SSISTA Sugar Journal. 16(3)23-57.

Robert Worsing. 1995 Rural Rescue and Emergency Care. American Academy of orthopaedic Surgeons.

Seputar Sampah, Majalah Percik, Vol 5 tahun 1, Agustus 2004.

Sitkey G. 1986. Mechanics of Agricultural Material.Elsevier. Amsterdam.

Sudrajat. 2006. Mengelola Sampah Perkotaan. Penebar Swadaya. Jakarta.

Sukatna, 2005, Hasil Melimpah dari Plastik Sampah. Majalah Pengusaha Peluang Usaha dan Solusinya, http://www.majalah pengusaha.com/2005.

Sumule, 2006. Produk Teknologi Berwawasan Lingkungan. Staf Peneliti pada direktorat Pengkajian Ilmu Dasar dan Terapan, BPP Teknologi. http://www.handling.com/apakbar/bas ic data.

Sularso. MSME, dan Kiyotkat Suga, 1987. Dasar Perencanaan dan Pemilihan Elemen Mesin. Penerbit Pradyana Paramita.

Umar Sukrisno, 1983. Bagian-bagian Mesin dan Merencana. Penerbit Airlangga.

Van Vlack Laurence, 1994, Ilmu dan Teknologi Bahan, Jakarta Penerbit Erlangga

Wahyu. K. 2011. Desain Dan Kinerja Unit Pemotong Serasah Tebu Dengan Menggunakan Pisau Tipe Reel, (Tesis). Pascasarjana Institut Pertanian Bogor. Bogor. 